\title{
Object Constraint Language
}

National Cancer Institute

\section{Source}

National Cancer Institute. Object Constraint Language. NCI Thesaurus. Code C80515.

An extension to UML that provides constraint and object query expressions on an objectoriented model that cannot otherwise be expressed by diagrammatic notation, providing expressions that have neither the ambiguities of natural language nor the inherent difficulty of using complex mathematics. 